\title{
Effect Of Setback Irregularity On Elastic Seismic Demand Of Reinforced Concrete Building
}

\author{
Bereket Netsanet Bekele \\ ${ }^{1}$ Lecturer, Department of Civil Engineering, Wolaita Sodo University, Ethiopia \\ Email: bekelebereket200@gmail.com
}

\begin{abstract}
Now a day, many building have not regular configuration both in plan and in elevation due to different functional and aesthetic requirements. Hence, the evaluation of the seismic behavior of reinforced concrete building with plan and elevation irregularity is required. In this study the evaluation of elastic seismic demand of reinforced concrete building with setback irregularity was carried out. The standards used for analysis of base case building and vertical irregular building using response spectrum analysis (RSA) method are adopted according to the provision of ES EN 1998-1:2015. The evaluation of elastic demand of building (story displacement, story drift, story shear and base shear) were assessed in detail using seven different building. Story eight and Story twelve reinforced concrete building with different stiffness and setback irregularity were selected and their responses were compared with the ones of a corresponding base case was done using ETABS 2016.1.0 software. The setback of building is formed by the abrupt reduction in different floor area along the height of the building.The seismic response of setback buildings was found to be significantly different from the base case building, according to the findings of this study.The findings reveal that the seismic response variation of setback building from the base case is dependent not only on the size of the irregularity, but also on the placement of the irregularity. This research compares the seismic response of reinforced concrete buildings with setbackirregularity to that of conventional buildings.
\end{abstract}

\section{Key word: setback, base shear, story displacement}

\section{INTRODUCTION}

Recently, modern design increasingly uses irregular structures, in plan or elevation, because of their functional and aesthetic value, this has motivated researchers and engineers to investigate the behavior and the performance of these structures during earthquakes. To take into account the effect of setbacks in buildings subjected to seismic action and to improve the seismic behavior of these structures, several research studies have been conducted. (M. S. Azad, 2019)investigated the effect of abrupt change of floor area percentage on the seismic response of buildings. The study was carried out by considering the following different shapes of six-story buildings with setback percentages of $33.33 \%$ and $66.67 \%$ along with the height of the building. The results show that the setback percentages significantly govern the seismic response of the structures[1]. Also, Bhosale et al.(A. S. Bhosale, 2017)studied the seismic behavior, in terms of inter-story drift ratio (IDR) and fragility curves, for buildings that have different vertical irregularities, including two models with setback were considered, one with a single setback (SB) and the other with multiple setbacks (ST). These models were subjected to 44 ground motions. The results of this investigation show that the (ST) model is the least vulnerable, but these two models need to be carefully studied to validate the requirements recommended by the design codes. (Asad, 2014)conducted a study on the seismic performance of multi-story frames, designed according to the Iranian seismic code (Standard 2800),[2] with a setback along with the height of the building. 35 reinforced concrete frames were subjected to earthquakes with different intensities. Then, 
the seismic performance is evaluated in terms of the inter-story drift ratio of the structure and the maximum rotation of its elements. From the results of their study, it was concluded that irregular buildings designed according to Iranian code seem to need to be improved to define and suggest new indicators to predict seismic behavior for this type of structure. (Lu, 593-614)assessed the seismic behavior of a 58-storey building.[3] Non-linear dynamic time-history analyses were conducted. The most remarkable results in their study indicate that there is an excessive concentration of damage in the floors adjacent to the setbacks. Likewise, (A. Habibi, 2018)assessed the seismic performance of several multistorey reinforced concrete moment resisting frames containing different types of setbacks. From their study, it was shown that the structural failure starts for the elements located in the approximate of the setbacks. So, it is necessary to strengthen these elements by introducing appropriate modifications to the design methodologies of seismic code applicated in Iran. (Sarkar, 2010)studied the vertical irregularity for 78 stepped buildings to provide a new approach to quantify the irregularity.Then the authors proposed a correction factor to the empirical formula of the code for the fundamental period to make it applicable to these types of buildings.(Wood, 1992) : The reaction of two small-scale models was used to explore the seismic behave or of reinforced concrete frames with setbacks. She discovered that the first mode dominates the displacement and shear response of setback buildings, but that higher modes dominate the acceleration response. She came to the conclusion that the reaction of a setback structure is identical to that of a regular structure, and hence no special design considerations are required.(Wong, 1994): When comparing the seismic response of structures with setback irregularity to the static code approach, it was discovered that buildings with setback irregularity had greater modal masses, resulting in a different seismic load distribution.(Fragiadakis, 2005): The seismic response of building systems with an uneven vertical distribution of strength and stiffness was determined. After conducting the analytical analysis, it was determined that the structure's seismic performance was dependent on the type and location of irregularities, as well as the degree of seismic excitation.[4]

The purpose of this study is to look into the effect of setback on elastic seismic demand of reinforced concrete buildings that had setbacks irregularities. The criteria and requirements for applying response spectrum analysis (RSA) to analyze base case and vertical irregular buildings are based on the provisions of ES EN 1998-1:2015. seven different buildings were used to compare elastic seismic demand of the building.[5]

As a result, vertical abnormalities have a significant impact on the seismic performance of structures. The dynamic characteristics of these buildings differ from conventional buildings due to height-based changes in stiffness and mass. The method of analysis to be employed is the most significant point when a structure has irregularities in mass, stiffness, strength, or vertical geometric irregularity. Building analysis methods are recommended in many nations' existing building design codes based on this. Linear static, linear dynamic, nonlinear static, and nonlinear dynamic analysis are the four types of analysis methods. The first two are suitable among various methods of analysis. [6][7]

Setback in buildings introduces staggered abrupt reductions in floor area along the height of the building. setback building form is becoming increasingly popular in modern multi-storey building construction mainly because of its functional and aesthetic architecture. In particular, such a setback form provides for adequate daylight and ventilation for the lower storey in an urban locality with closely spaced tall buildings. This setback affects the mass, strength, stiffness, center of mass and center of stiffness of setback building. Dynamic characteristics of such buildings differ from the regular building due to changes in geometrical and structural property. So effective procedures to 
estimate seismic elastic demands needed. Many investigations have been performed to understand the behavior of irregular structures as well as setback structures and to ascertain method of improving their performance. But it is seen that most of the previous studies were based on pervious code of the building and were not satisfied the current code requirements. So, there is a need to study the seismic performance of setback structures designed by recent codes the adequacy of current seismic design requirements for setback buildings.[11][12]

\subsection{Objective}

The objective of this study is:

To study the effect setback irregularities on the distribution of elastic seismic demands (story displacement, story drift, story shear, and base shear) over height of 8 and 12 story reinforced concrete buildings.

$>$ To compare the elastic seismic demand of setback building with the regular building.

The scope of this study only RC buildings are considered, consider only vertical irregularity, Column was modeled as fixed to the base, The contribution of infill wall to the stiffness was not considered and the effect of soil structure interaction is ignored.

\section{METHODOLOGY}

There is a methodology that was designed to attain the objectives of this study work in the steps necessary to complete it. The following is a list of the methods that was employed.

1. A review of the literature by several researchers.

2. The types of reinforced concrete buildings that will be employed in the analysis and modeling.

3. ETABS 2016 was used to model the selected buildings. Version 1.0 of the software.

4. The criteria and requirements for applying response spectrum analysis (RSA) to analyze base case and vertical irregular buildings are based on the provisions of ES EN 1998-1:2015.

5. seven distinct buildings were used to analyze the comparison of fundamental period and elastic demand of building (story displacement, story drift, story shear, and base shear).

The choice of study approach used has a significant impact on the seismic response of building systems. Because of its simplicity, linear static analysis approaches were used in previous years. Although these strategies produced safe designs, they were found to be overly cautious. The development of advanced computers and analytic programs allowed researchers to take a more rational approach by simulating genuine earthquakes on building models to generate accurate seismic responses; these methods were classified as dynamic analysis. Static and dynamic analysis are further divided into linear and nonlinear approaches based on the structural members' force-deformation relationship. (Varadharajan, 2014).

Equivalent static analysis is not used in this study since the building to be used is not regular and hence does not meet the ES EN (1998-1]., 2015) criteria to use this method. As a result, linear dynamic analysis (response spectrum analysis) is utilized to assess elastic reactions. The research is based on a three-dimensional RC structure with stiffness and uneven setbacks. Special concrete moment resisting 3D frames with stiffness and setback irregularity are investigated in order to determine seismic response of building structures. For the investigation, various building geometries were used. Buildings of eight and twelve stories are being explored. Because the buildings are symmetrical in 
plan, torsion isn't a factor; all floors are presumed to be rigid. Setback abnormalities is introduced at various points along the building's height. There are seven different building geometries, two regular and five irregular reinforced concrete building is considered. Presents the elevation of all seven different geometries of building. Reinforced concrete building with setback are named as regular story eight (RS8.), regular story twelve (RSS12.), irregular story eight with setback at story three (IRR.S8.SB3), irregular story eight building with setback at story seven (IRR.S8.SB7), irregular story twelve with setback at story two (IRR.S12.SB2), irregular story twelve with setback at story seven (IRR.S12.SB7) and irregular story twelve with setback at story nine (IRR.S12.SB9) depending on the location setback introduced.[8]

\section{ANALYSIS}

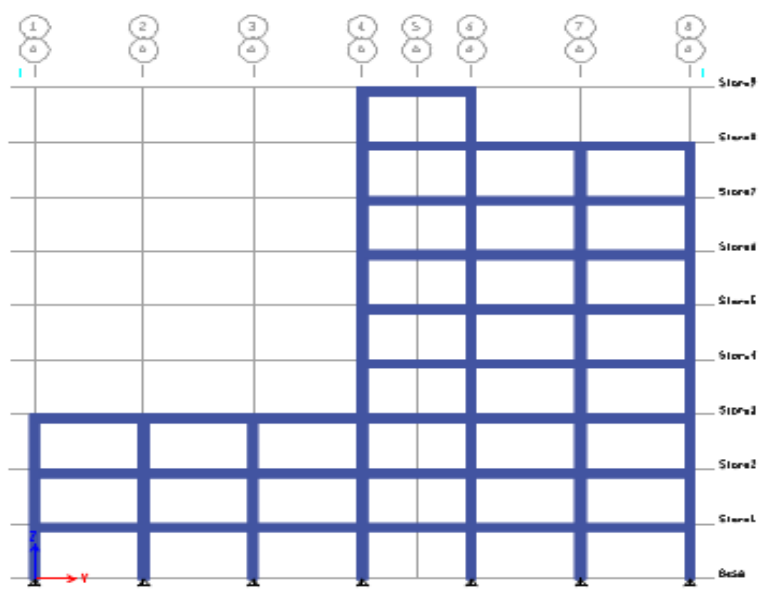

Figure 1:Story 8 Building Frame with Setback Irregularity at Story 3 (IRR.S8.SB3)

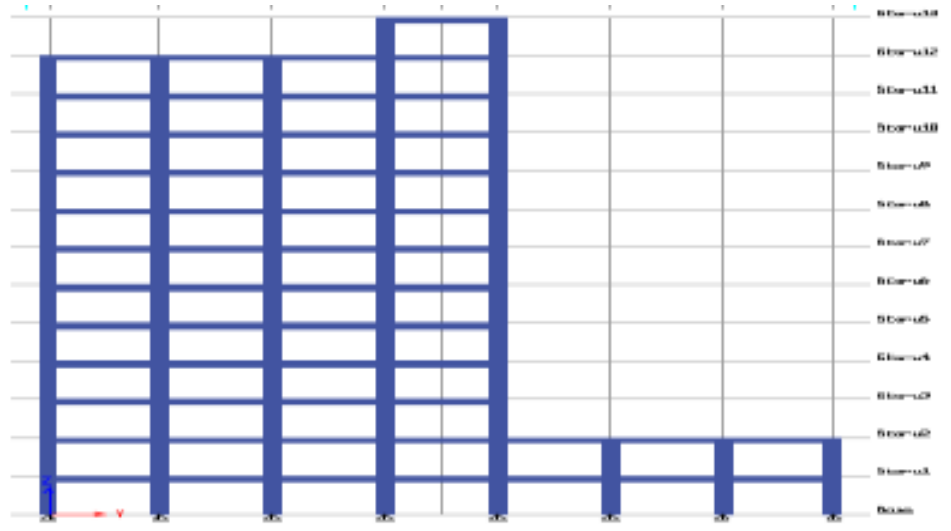

Figure 2Story 12 Building Frame with Setback at Story 2 (IRR.S12. SB2) 
All of the building structures are analyzed according to EBCS EN ([1998-1], ES EN, 2015) ETABS software is used for the analysis

Table 1: The Material and The Parameter Used in This Analysis

\begin{tabular}{|c|c|c|c|}
\hline \multicolumn{2}{|l|}{ Peak ground acceleration $\mathrm{a}_{\mathrm{g}}$} & \multicolumn{2}{|l|}{$0.1 \mathrm{~g}$} \\
\hline \multicolumn{2}{|l|}{ Concrete } & \multicolumn{2}{|c|}{ C-30 } \\
\hline \multicolumn{2}{|l|}{ Rebar } & \multicolumn{2}{|l|}{ S-500 } \\
\hline \multicolumn{2}{|l|}{ Modulus of elasticity of concrete } & \multicolumn{2}{|l|}{$33 \mathrm{GPa}$} \\
\hline \multicolumn{2}{|l|}{ Modulus of elasticity of steel } & \multicolumn{2}{|l|}{$200 \mathrm{GPa}$} \\
\hline \multicolumn{2}{|l|}{ Importance factor } & \multicolumn{2}{|c|}{1} \\
\hline \multicolumn{2}{|l|}{ Earthquake zone } & \multicolumn{2}{|l|}{ Zone 2} \\
\hline \multicolumn{2}{|l|}{ Damping ratio } & \multicolumn{2}{|l|}{$5 \%$} \\
\hline \multicolumn{2}{|l|}{ Soil class } & \multicolumn{2}{|c|}{$\mathrm{C}$} \\
\hline \multicolumn{2}{|l|}{ Building type } & \multicolumn{2}{|c|}{ Special moment resisting RC frame } \\
\hline Number of story building & Beam dimension $(\mathrm{mm}$ & & Column dimension $(\mathrm{mm})$ \\
\hline 8 & $300 \times 400$ & & $400 \times 400$ \\
\hline 12 & $350 \times 450$ & & $600 \times 600$ \\
\hline
\end{tabular}

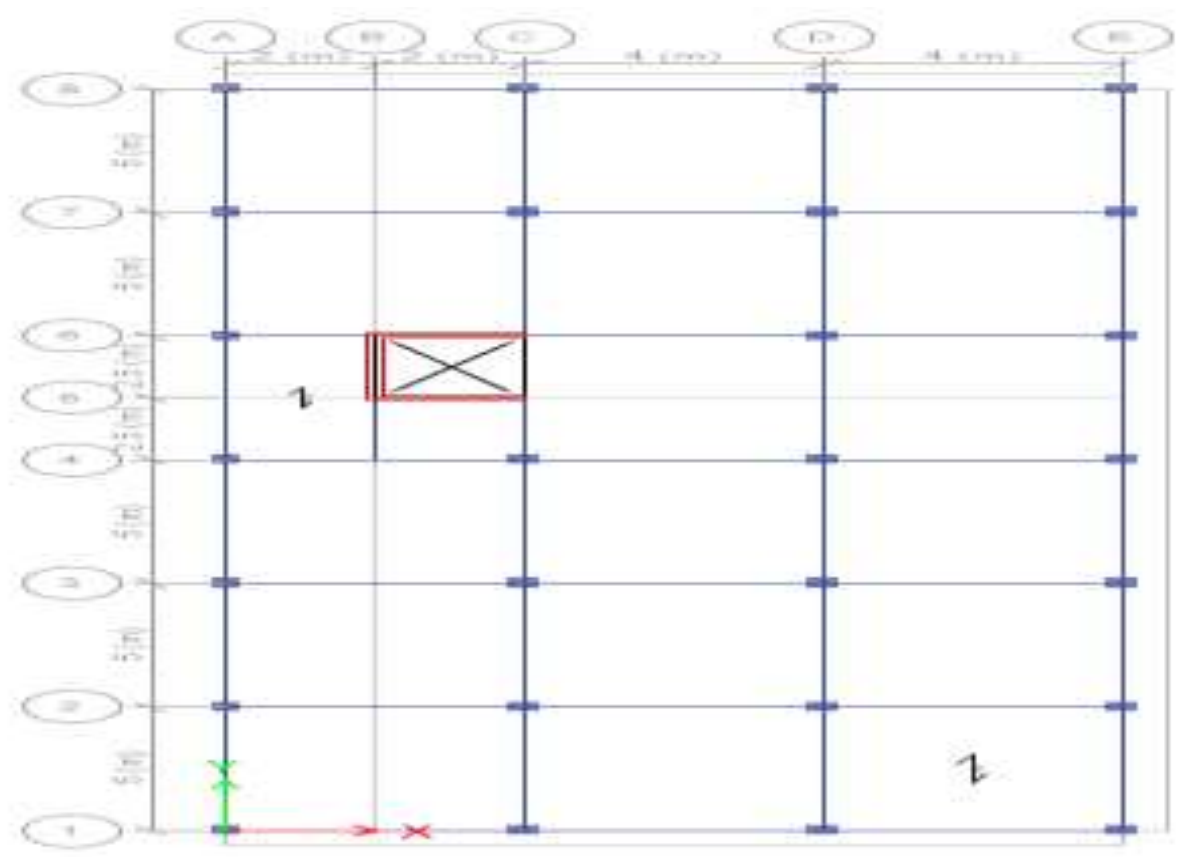

Figure 3: Plane of Story Eight Building. 


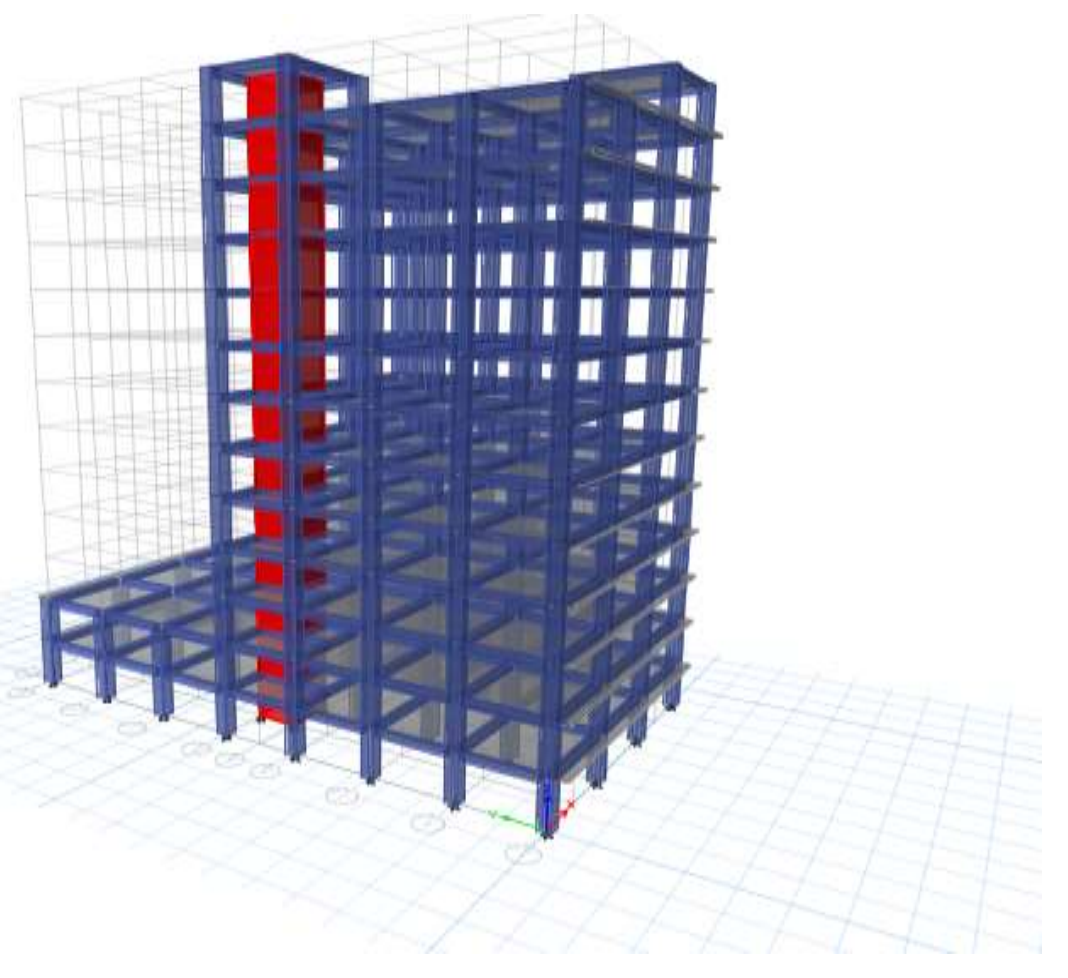

Figure 4: 3d of Story Twelve-Setback Building

\section{RESULT AND DISCUSSION}

Setback is abrupt reduction of the lateral dimension of the building at specific levels of elevation. This type of vertical geometric irregular building is known as setback building. Setback buildings with geometric irregularity (both in elevation and in plan) are now increasingly encountered in modern urban construction. Setback buildings are characterized by staggered abrupt reductions in floor area along the height of the building, with consequent drops in mass, strength and stiffness[9][10].

The goal of this section is to assess how setback irregularity affects story shear, story drift, base shear, and maximum story displacement. In comparison to the base scenario, the variation of elastic seismic demand is assessed for setback irregularity of story 8 and story 12 buildings. To evaluate elastic seismic demand, response spectrum was performed on regular and irregular buildings. In this section two-setback irregular story 8 building, three setback irregular story 12 building, one regular story 8 building and one story 12 regular building analysis is performed with response spectrum to evaluate variation of elastic seismic demand of setback irregular building with respect to base case. 


\section{1 .Effect of setback irregularity on story displacement}

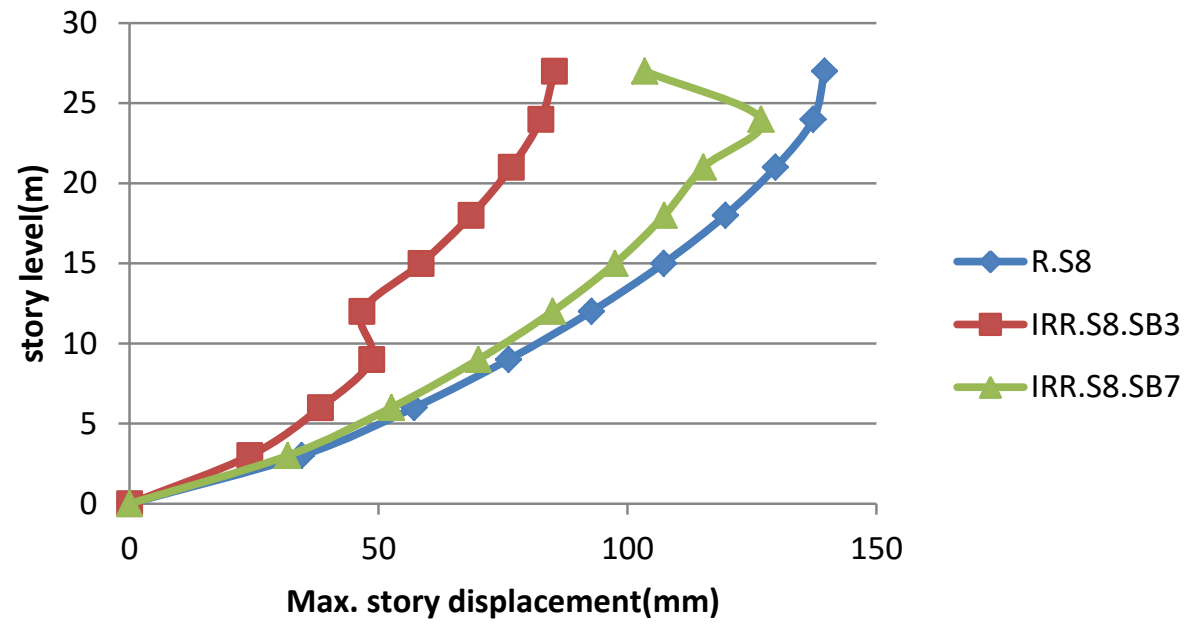

Figure 5: Maximum Story Displacement of Story 8 Building with Setback at Third Story and Seventh Story.

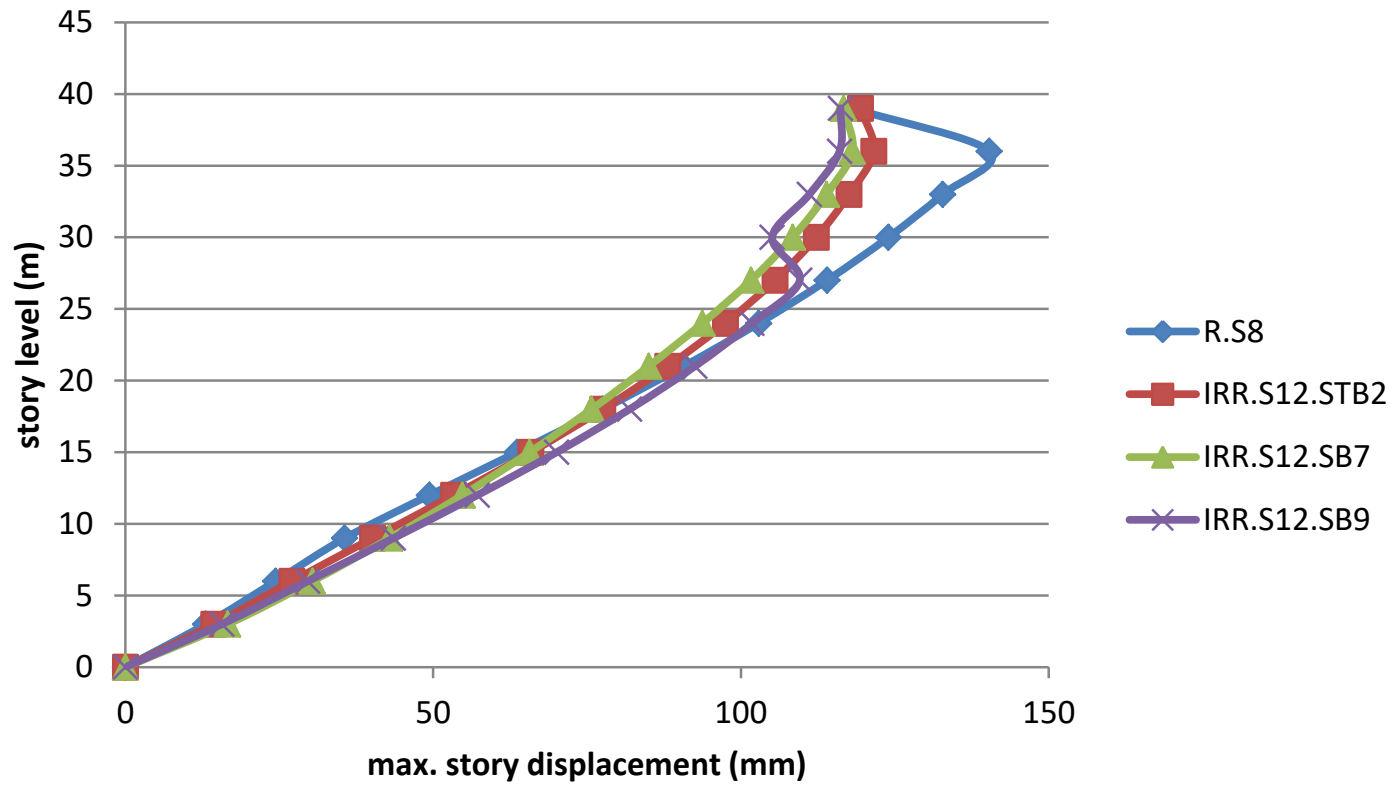

Figure 6: Maximum Story Displacement of Story 12 Building with Setback at Second Story, Seventh Story and Ninth Story. 


\subsection{Effect of setback irregularity on story drift}

Generally, the maximum Story drift of 8-story building and 12-story building is decreases with setback irregularity compared to the base case.

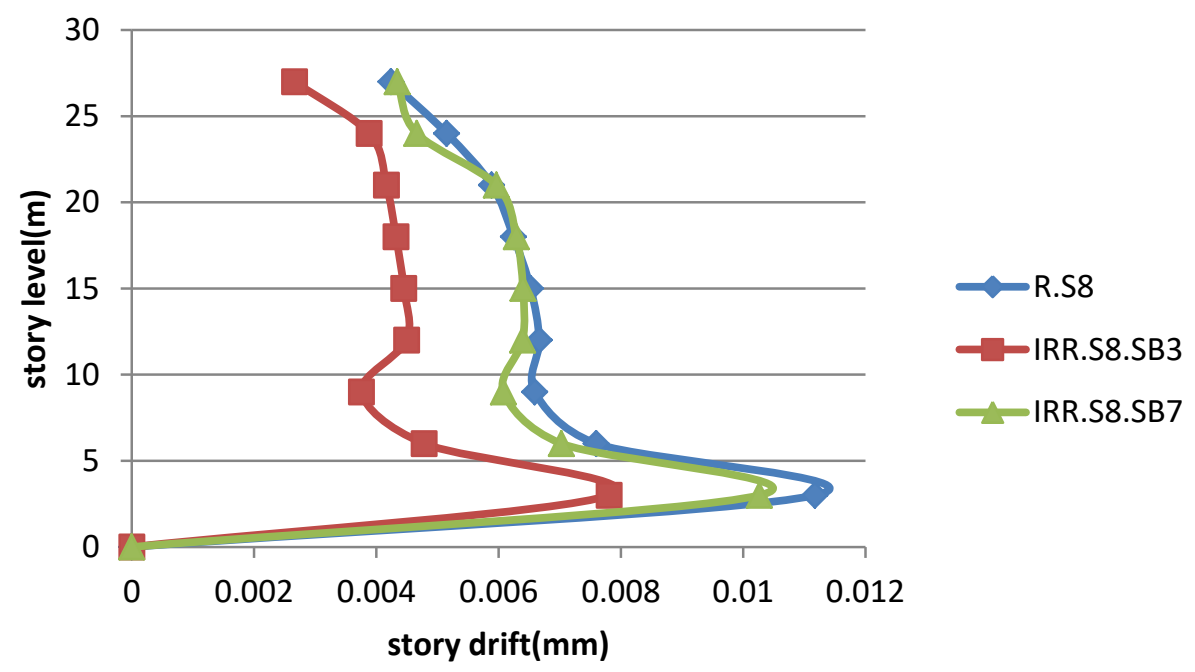

Figure 7: Maximum Story Drifts of Story 8 Building with Setback at Third Story and Seventh Story.

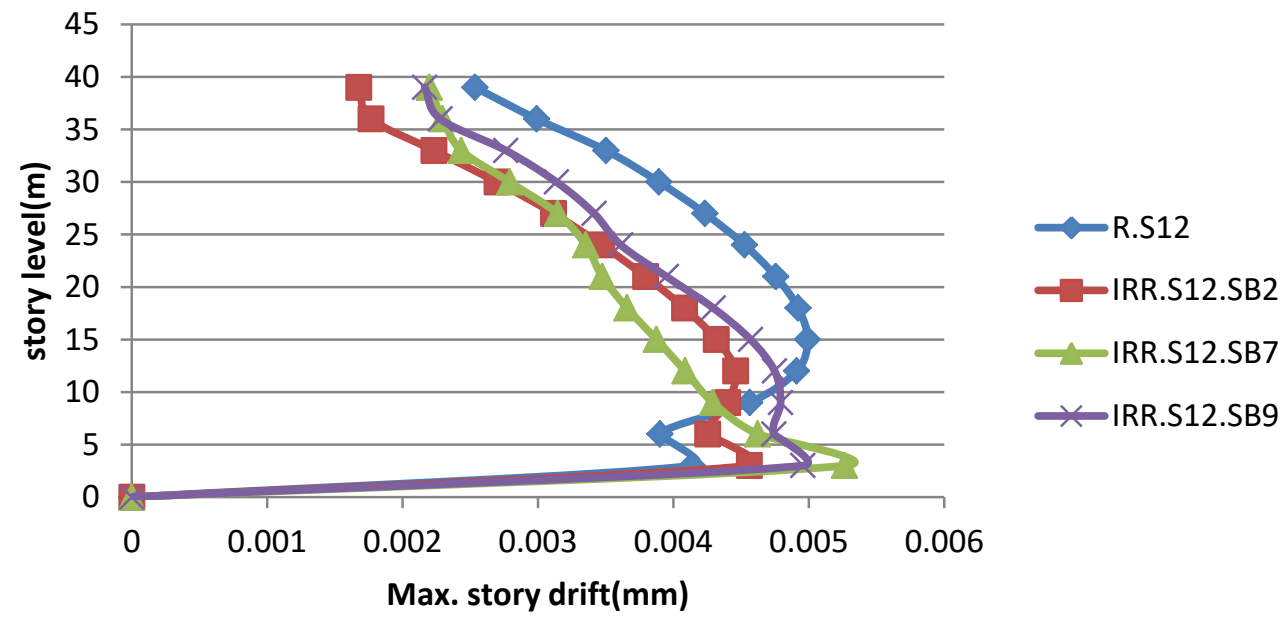

Figure 8: Maximum Story Drifts of Story 12 Building with Setback at Second Story, Seventh Story and Ninth Story. 


\subsection{Effect of setback irregularity on base shear}

The base shear for story 8 building with a setback at the third story is decreased base shear about $13.461 \%$ compared to base case and setback at the seventh story is increased base shear about $0.241 \%$ compared to the base case. The base shear for story 12 building with a setback at the second story is decreased base shear about 54.989\% compared to the base case, setback at the seventh story is decreases base shear about $32.502 \%$ compared to the base case and setback at ninth-story decreases about $20.916 \%$ compared to the base case. Generally, base shear is decreasing due to setbacks for both story 8 and 12 buildings, when compared to the base case.

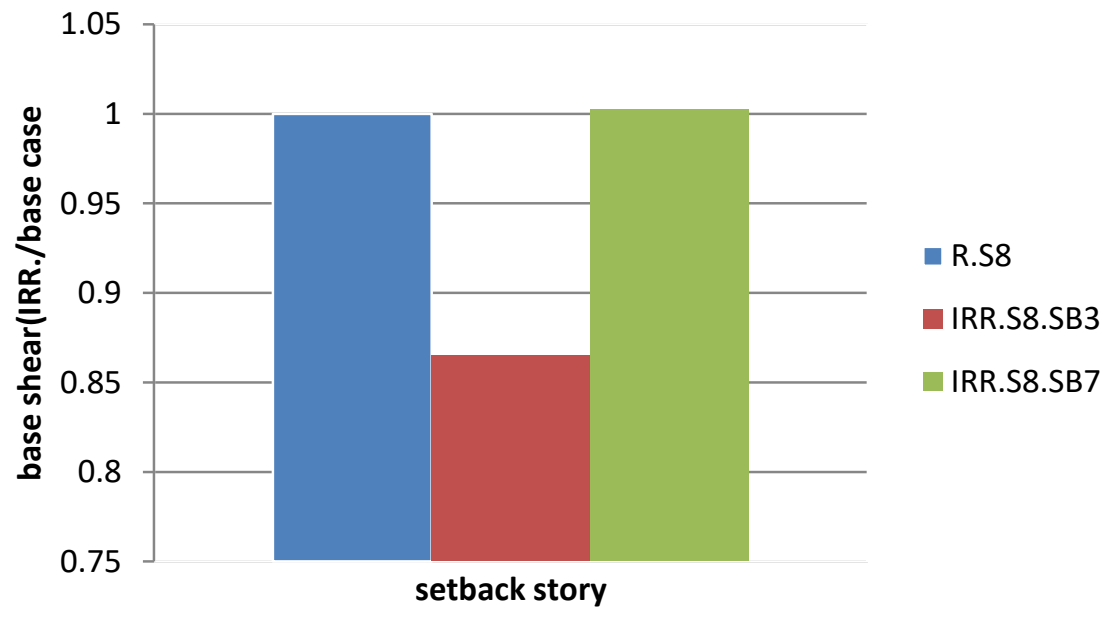

Figure 9:Base Shear of Story 8 Building with Setback at Third Story and Seventh Story

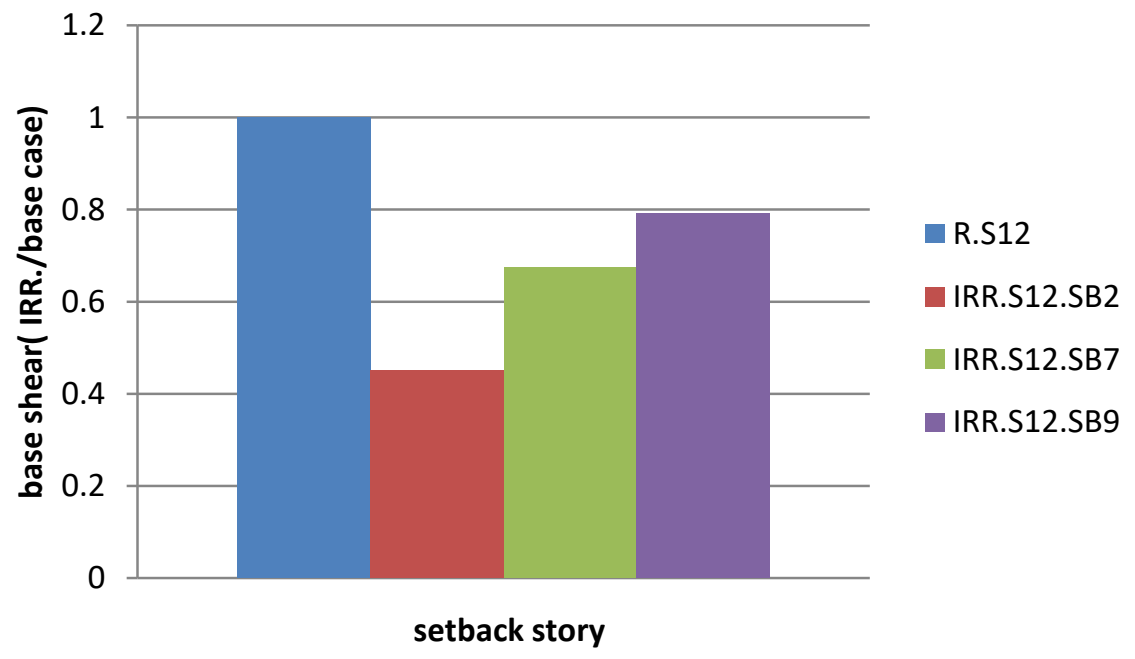

Figure 10: Base shear of story 12 building with setback at second story, seventh story and ninth story. 


\subsection{Effect of setback irregularity on story shear}

The maximum story shear for story 8 building with setback at third story is decreases story shear about $61.953 \%$ compared to base case and setback at seventh story is decrease story shear about $30.565 \%$ compared to base case. The maximum story shear for story 12 building with setback at second story is decreases story shear about $61.839 \%$ compared to base case, setback at seventh story is decreases story shear about $45.766 \%$ compared to base case and setback at ninth story decreases about $41.971 \%$ compared to base case.Generally, story shear is decreases due to setback for both story 8 and 12 building, when compared to the base case.

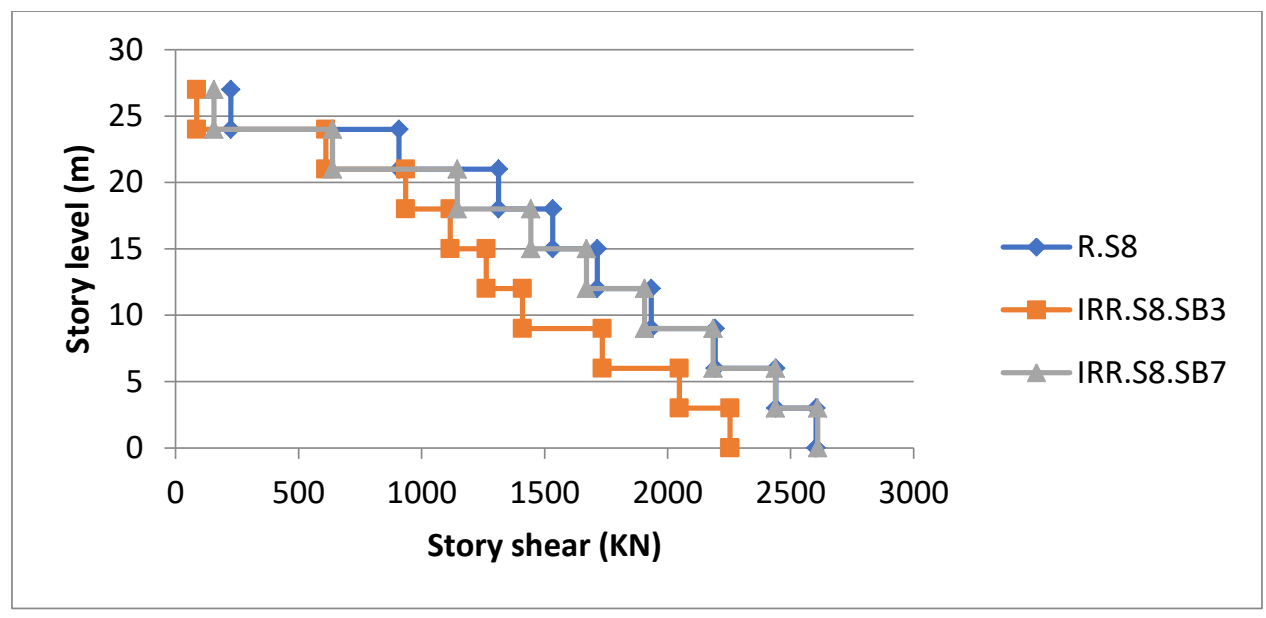

Figure 11: Story shear of story 8 building with setback at third story and seventh story.

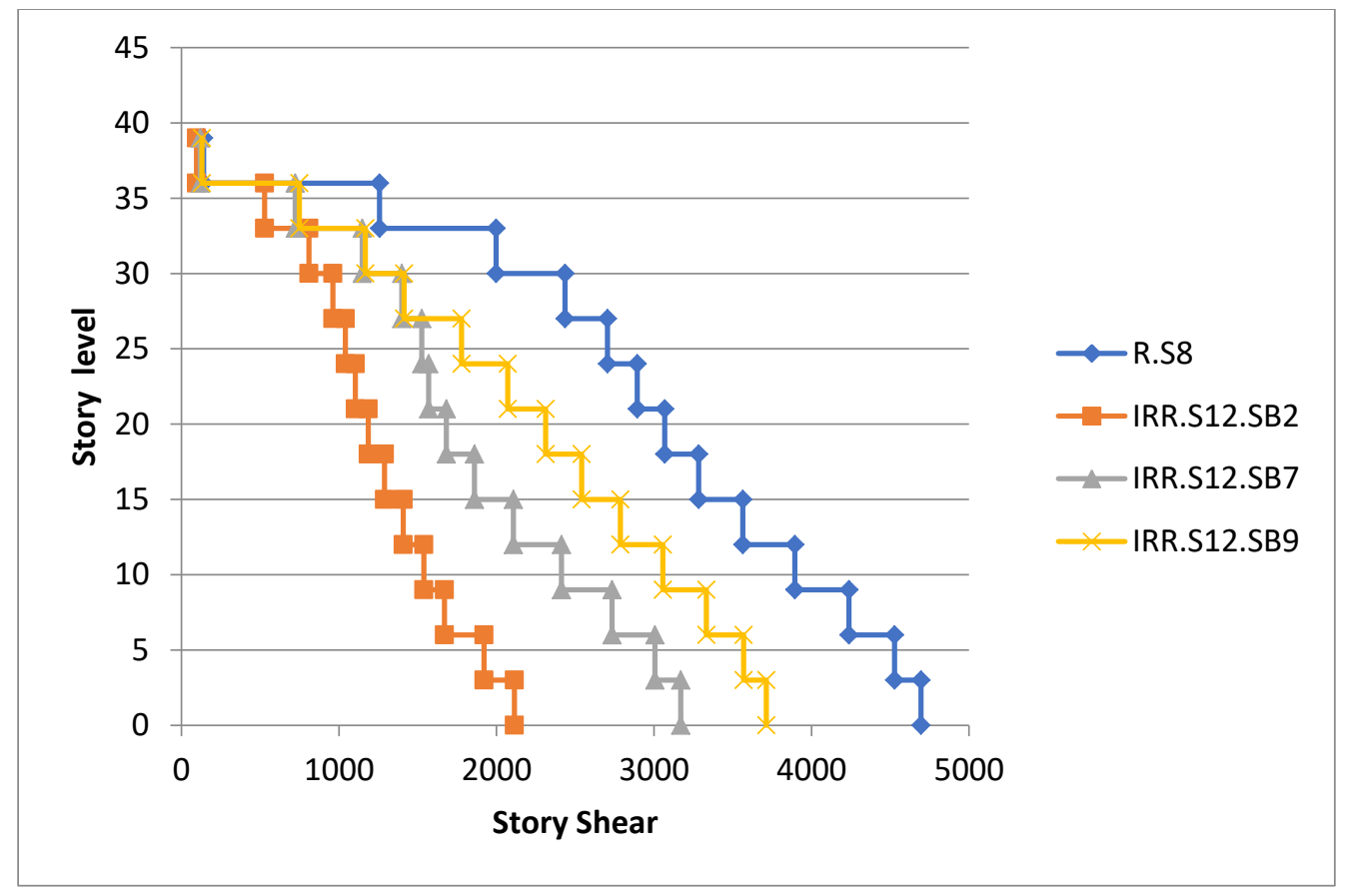

Figure 12: Story Shear of Story 8 Building with Setback at Third Story and Seventh Story. 


\section{CONCLUSION}

In this study the seismic behavior of story- $8 \mathrm{RC}$ building and story-12 RC building with setback irregularities are studied. The setbacks are introduced at different story level along the height of building. For story-8, building the setback is introduced at story three and at story seven, for story-12 building the setback is introduced at story two, at story seven and at story nine.The responses of reinforced concrete building with setback irregularities have been evaluated. The effect of setback irregularity is assessed by evaluating elastic seismic demand of building such as base shear, story displacement, story drift and story shear. Therefore, based on the work presented in this study the following conclusion can be drawn.

$\checkmark \quad$ The base shear is decreases with setback irregularity for both story eight and story twelve building with respect to base case building.

$\checkmark \quad$ The story shear is decreases with setback irregularity for both story eight and story twelve building with respect to base case building.

$\checkmark \quad$ The study shows that story displacement of setback building has significant change compared to the regular building for both story eight and twelve building.

$\checkmark \quad$ The maximum Story drift of 8-story building and 12-story building is decreases with setback irregularity compared to the base case.

$\checkmark$ Generally, story shear is decreases due to setback for both story 8 and 12 building, when compared to the base case.

\section{ACKNOWLEDGMENT:}

We would like to thank wolaita sodo university for the motivating us to work research. Special thanks also support the respondents for dedicating their time and sharing their ideas and concepts compassionately. 


\section{References}

[1] [1998-1], ES EN. (2015). Design of Structures for Earthquake Resistance. Ethiopian Building Code Standard-8, part-1.

[2] All-Ali AAK, K. H. (1998). "Effect of Vertical Irregularities on Seismic. Blume earthquake engineering center, Stanford, 130.

[3] Das, S. a. (2003). "Seismic Design Aspects of Vertically Irregular". Earthquake Spectra, 19(3), pp. 455-477.

[4] Dr.A.Paulmakesh, Gizachew Markos Makebo October 2021The Effect of Glass Fiber on Concrete and Reinforced Concrete Beam under Elevated Temperature, Journal of Physics Conference Series 2040(1):012027, DOI:10.1088/1742-6596/2040/1/012027

[5] Fragiadakis, M. V. (2005). Evaluation of the influence of vertical Stiffness irregularities onthe seismic response of a 9-story steelframell. In Proceedings of the 4th European workshop on the seismic behavior of irregular and complex structures, CD ROM. Thessaloniki.

[6] Dr.A. Paulmakesh, Dec 2021, "Analysis of uncertainty in a construction project" YMER journal, Vol 20,Issue 12, pg.no 324-332.

[7] Humar, J. a. (1977). Earthquake Response of Steel-Framed Multistory Buildings with SetBacks. Earthquake Engineering \& Structural Dynamics,, 5(1), pp.15-39.

[8] Dr.A. Paulmakesh, Yimam Mohammed Yimer April 2021, "Implementation of Project Management for Strategy Realisation" Journal of University shanghai for Science and Technology, Volume 23, Issue 10,Pg.No 887-892

[9] K, M. V. (2014). "Seismic Behaviour of Setback Buildings". international journal of innovative research in science, engineering and technology,, 3, pp.235-241.

[10] Poonam, K. A. (2012). Study of Response of Structural Irregular Building Frames to Seismic Excitations. International Journal of Civil, Structural, Environmental and Infrastructure Engineering Research and Development (IJCSEIERD), 2(2), 25-31.

[11] Dr.A. Paulmakesh, Gizachew Markos Makebo April 2021, "Management of contracts for Durable structures" Innovations, Number 64,Pg 1044-1054

[12] Wong, C. a. (1994). Seismic Loading for Buildings with Setbacks. Canadian Journal of Civil Engineering, 21(5), pp. 863-871. 